\title{
Plant traits explain the success of vacuum harvesting as a method of seed collection for the restoration of species-rich grasslands
}

\author{
Marek Czerwiński ${ }^{1,3}$ (D) Ben A. Woodcock ${ }^{2} \cdot{\text { Barbara Golińska }{ }^{1} \cdot \text { Wiesław Dembek }}^{3}$
}

Received: 29 December 2016 / Revised: 28 August 2017 / Accepted: 13 November 2017 / Published online: 19 January 2018

(c) The Author(s) 2018. This article is an open access publication

\begin{abstract}
Grassland restoration is a key measure for re-establishing damaged floral communities. As seed banks are often degraded, methods are needed to overcome dispersal limitation of the remnant vegetation. One approach is to vacuum harvest seeds from donor sites. While this is a cost-effective method, individual species' traits describing reproduction methods and dispersal mechanisms may affect the success with which seeds are collected and subsequently germinate. We collected seeds using low-cost vacuum harvesters in species-rich meadows in Poland. We predicted the relative success with which seedlings emerged from this collected material with respect to their percentage cover in the donor sites on the basis of individual species' functional traits. Prolific species that rely on seed as opposed to vegetative reproduction, and those that germinate in late summer/autumn, exhibited the highest level of emergence. To a lesser extent, drought-tolerant or shade-intolerant species were well represented in the collected material. There was also weak evidence that wind-dispersed seeds would have a higher likelihood of being collected by this method. Our results suggest that vacuum harvesting is a valuable method to collect seeds for use in grassland restoration; however, it has limitations. In particular, additional methods may be needed to introduce into grassland restoration sites the propagules of species that vegetatively reproduce or seed early. The overrepresentation of species that produce large numbers of seed may potentially introduce priority effects that could also have unintended long-term implications for the structure of the floral community.
\end{abstract}

Keywords Semi-natural grassland $\cdot$ Functional traits $\cdot$ Provenance $\cdot$ Restoration $\cdot$ Species characteristics $\cdot$ Molinia meadows

\section{Introduction}

The successful restoration of species-rich grasslands is typically dependent on the artificial introduction of seed from species that are characteristic of the target habitat type (Stevenson et al. 1997; Pywell et al. 2003; Edwards et al. 2007). This is due to dispersal being a constraining factor during

Electronic supplementary material The online version of this article (https://doi.org/10.1007/s11355-017-0341-y) contains supplementary material, which is available to authorized users.

Marek Czerwiński

m.czerwinski@up.poznan.pl

1 Department of Grassland and Natural Landscape Sciences, Poznań University of Life Sciences, ul. Dojazd 11, 60-632 Poznan, Poland

2 NERC Centre for Ecology and Hydrology, Crowmarsh Gifford, Wallingford, Oxfordshire OX13 6NT, UK

3 Institute of Technology and Life Sciences, Falenty, Al. Hrabska 3, 05-090 Raszyn, Poland grassland restoration for many plant species, particularly where the existing seed bank has become largely impoverished owing to long-term changes in land management (Bischoff 2002; Donath et al. 2003; Thomson et al. 2011). Dispersal distances for individual species are typically a product of a wide variety of mechanisms that depend on wind, gravity, water and the activity of living organisms (Ghazoul 2005). Differences in individual species' functional traits that affect dispersal by these mechanisms could have a significant influence on the establishment of these species in grassland restoration sites (Pywell et al. 2003; Edwards et al. 2007).

A wide variety of approaches have been used to collect seed for grassland restoration, including the sowing of seeds originating from commercially grown stock, as well as the collection of local provenance seeds from the swards of species-rich grasslands (Morgan and Collicutt 1994; Jones et al. 1999; Pywell et al. 2003; Edwards et al. 2007). Normally, seeds from existing species-rich grasslands are transferred by harvesting green hay and then spreading it along with 
the diaspores it contains onto sites targeted for restoration (Morgan and Collicutt 1994; Jones et al. 1999; Edwards et al. 2007). Unfortunately, this approach relies on expensive machinery that is not always widely available. As a result, there has been interest in the use of seed vacuum harvesters that can be converted at low cost from widely available gardener's leaf blowers/lawn vacuums (Briggs 2001; Kalmbacher et al. 2005). Such vacuum harvesters are both simple and cost effective, collecting large number of seeds without compromising germination rates when sown (Stevenson et al. 1997; Riley et al. 2004; Kiehl et al. 2010). Typically the aperture of the sucking unit ranges from $10-15 \mathrm{~cm}$ in diameter for hand-held devices, to $>1 \mathrm{~m}$ for heavier tractormounted harvesters (Scotton et al. 2011).

As for many seed-collecting methods, the use of suction harvesting may be expected to introduce bias towards particular species. For example, those functional groups of plants that use wind-based dispersal mechanism or have very light seeds may be expected to be preferentially collected. It is also possible that the collection of seed with vacuum harvesters is more efficient for plant species characteristic of dry habitats. In those habitats, gaps are relatively large and frequent, which increases the chance for successful establishment from seed (Grime 2002). While these problems have received limited attention in the literature, such sampling bias could potentially affect what species become established during grassland restoration (Stevenson et al. 1997; Riley et al. 2004; Kiehl et al. 2010). The order with which species establish into new grasslands, so called 'priority effects', can have long-term ramifications for the structure of plant communities (Young et al. 2005). If suction sampling of seeds preferentially biases certain plant functional types then such priority effects may undermine the validity of vacuum harvesting as a method for promoting grassland restoration (Young et al. 2005).

In this paper we assess the use of vacuum harvesting as a method for seed collection during grassland restoration. We contrast the practical advantages of this method with its ecological effectiveness by testing whether the likelihood of collecting seeds during vacuum harvesting is dependent on key functional traits of individual species. We predict that the seed mixture collected with vacuum harvesting methods will be dominated by plant species which:

1. Produce large numbers of seed.

2. Put greater reproductive effort into seed as opposed to vegetative reproduction.

3. Utilise wind-based dispersal mechanisms.

4. Have seeds that ripen and are shed from the plant close to the time of suction.

5. Are typical of dry sites and sparse, open vegetation.

6. Develop inflorescences and release seed at a specific height.

\section{Materials and methods}

\section{Donor sites description}

Seeds were collected from 11 meadows with a total area of 4.22 ha within the Bagno Serebryskie Nature Reserve $\left(51^{\circ} 10^{\prime} \mathrm{N}, 23^{\circ} 32^{\prime} \mathrm{E}\right)$. The reserve is a complex mosaic of chalk-lake mires, species-rich Molinia meadows and orchidrich xerothermic grasslands. It is considered to be one of the most valuable calcareous fens in Poland and has importance at a European scale (Natura 2000 site). The meadows were composed of a mixture of Molinion spp. and Molinietalia caeruleae, Caricion davallianae, Festucetalia valesiacae and Arrhenatheretalia elatioris communities (Oberdorfer 1994; Kącki et al. 2013). The management of these communities was limited to sward cutting and removal once a year in autumn. Forty-two $5 \times 5$-m quadrats were used to assess plant community composition by vertical projection of percentage cover. These 42 quadrats were allocated across all sites in a manner proportional to their individual area (see Online Appendix A), although within individual meadows they were randomly located. The floral composition of the donor sites was assessed from 23 July to 4 September 2009.

\section{Vacuum harvesting of seeds}

Vacuum harvesting of seeds from the 11 meadows was undertaken using three petrol driven vacuums; two handheld vacuum harvesters (Echo ES-250ES; Echo, Lake Zurich, IL) and one walk-behind model supported by wheels (MEP Sirio; MEP-Electrolux, Spain). The hand-held vacuums collected seeds into a fine mesh bag installed onto the air outlet pipe. The MEP Sirio vacuumed seed via a hood mounted on the front, through a fan into a large collecting sack held behind. In both cases the air speed was ca. $65 \mathrm{~m} \mathrm{~s}^{-1}$ (Kioritz 2008; Coates 2015).

Seeds were vacuum harvested from 8 August 2009 to 10 September 2009 and again from 14 September 2009 to 10 October 2009. These two sampling periods allowed the maturation of seeds from different plant species and helped ensure samples were representative of the vegetation present. In all cases, suction harvesting occurred after nesting of grassland birds was completed and before the October sward cut of the meadows. Collection time to area ratio remained consistent for each meadow. Approximately $5 \mathrm{~m}^{3}$ of material composed of seed, chaff, soil particles and litter was collected across all meadows. The mass of the collected seeds could not be accurately determined as their separation from the chaff was unfeasible. A clear and unambiguous classification of the donor meadows by the occurring vegetation was not possible because of the uneven terrain and the associated diversification of plant communities within the 
meadows. For this reason, the collected material was bulked across all 11 meadows with subsequent analysis focusing on the efficiency of suction harvesting as a method of collecting the seeds of individual plant species (see below for details). The collected material from the two different suction harvesters was also bulked. This was done as the hand-held and wheeled harvesters were considered to be complementary. While the wheeled vacuum harvesters were the most efficient in terms of collecting volume of material, they had a practical limitation in that they were hard to carry to some meadows where access was limited. In addition, wheeled vacuums have only a few centimetres ground clearance and so are not adapted to uneven ground.

\section{Seed mixture analysis}

Directly after each collection, the vacuumed material was thoroughly mixed, deposited on canvas sheets in a barn and left to dry. Two percent of the volume of this material was removed (weighing $9 \mathrm{~kg}$ ) and was split into eight subsamples (each $1.125 \mathrm{~kg}$ ). Each of these samples was sieved through a $15-\mathrm{mm}$ mesh and stored under dry conditions at below $0{ }^{\circ} \mathrm{C}$ until February. Then the collected material was spread onto eight plastic trays, which were filled with sterilised soil taken from the donor area. Soil sterilisation (and the consequent seed bank deactivation) was accomplished by steaming for $30 \mathrm{~min}$ at $115{ }^{\circ} \mathrm{C}$ and $101325 \mathrm{~Pa}$ on 2 successive days. The trays were then deposited in a cold store at $6{ }^{\circ} \mathrm{C}$ for 7 weeks to break dormancy. From April 2010 the trays were kept in a greenhouse and watered to keep soil moist. Seedlings were identified as soon as possible and then removed. Seedlings which could not be identified were transplanted to a separate pot and grown on until more diagnostic characteristics developed. In winter 2010/2011 the trays were kept in the cold store and then moved back to the greenhouse until October 2011. Over 20,000 seedlings were identified, and ca. $98 \%$ of them emerged in the first year of the assessment.

Vacuum collection efficiency of individual species (sp) relative to their occurrence within the donor site meadows was defined using a collection rate index $\left(e_{s p}\right)$, where $e_{\mathrm{sp}}=\ln$ $\left(G_{\mathrm{sp}} / C_{\mathrm{sp}}\right)$; where $G_{\mathrm{sp}}$ is the percentage of all seedlings emerging from the vacuumed material represented by species sp, and $C_{\mathrm{sp}}$ is the average percentage cover of that same species observed in the harvested meadow sites. To derive a solution to this equation in cases where either the numerator or denominator were zero, a fixed value of 0.01 was added to both $G_{\mathrm{sp}}$ and $C_{\mathrm{sp}}$ scores. Species with a positive $e_{\mathrm{sp}}$ score were overrepresented in the emerged vacuum-harvested material relative to what would be expected from their percentage cover in the donor meadows, while species with a negative score were underrepresented. The combination of seedling counts in the nominator of the $e_{s p}$ index with plant coverage in the denominator made the entire index sensitive to species that produce more seeds per ramet, which was taken into account by including seed production per ramet in the regression model (see below).

\section{Traits and species selection}

A trait can be defined as any attribute that will influence a plant's establishment, survival or fitness, and plays a key role in determining establishment success during grassland restoration (Pywell et al. 2003; Woodcock et al. 2011). The following trait data were derived from the $\mathrm{D}^{3}$ Dispersal Database (Hintze et al. 2013), Biolflor Traitbase (Klotz et al. 2002), LEDA Traitbase (Kleyer et al. 2008) and the Database of Ecological Indicator Values of Vascular Plants of Poland (Zarzycki et al. 2002). For each of the species recorded in this study we defined the following functional traits:

1. Mode of reproduction, divided into the classes: (a) seed, (b) mostly by seed, (c) by seeds and vegetatively, (d) mostly vegetatively, and (e) vegetatively only; these categories were replaced by $1.00,0.75,0.50,0.25$, and 0.00 , respectively, to make the variables suitable for quantitative analysis.

2. Seed production, defined as the average number of seed per ramet/shoot (Kleyer et al. 2008).

3. Mean seed-releasing height, derived from the minimum and maximum releasing heights (Kleyer et al. 2008).

4. Time of seed shedding, which was the arithmetic mean of the first and the last month of seed shedding (Kleyer et al. 2008).

5. Seed longevity, which refers to seed survival in the soil (Kleyer et al. 2008).

6. Habitat preferences (realised ecological optima) of plant species in terms of light availability, soil moisture, and soil fertility given by species ecological indicator values (Zarzycki et al. 2002).

7. Seed dispersal by wind expressed in terms of the anemochory ranking index (Hintze et al. 2013). The index was calculated as a percentile rank of the wind dispersal potential of a given species in relation to wind dispersal potentials of all species for which data were available. Seed terminal velocity (maximum speed when falling in still air) was used as an indicator of anemochory potential. Since the effect of seed terminal velocity incorporates the effects of seed size, shape, and weight (Greene and Johnson 1993), none of these characteristics was considered separately to avoid covariance between these effects.

Both reproduction mode and seed production were included in the analysis because the correlation coefficient 
between them for the considered species group was only -0.06 . The information on seed longevity was used to check if the conditions and period of storing seeds influenced the results of the seedling emergence analysis. It was taken into consideration that the viability of species that do not create a seed bank remained high due to keeping them at a temperature well below $0{ }^{\circ} \mathrm{C}$ throughout the winter, which was exceptionally cold in the year of the investigations. In ca. $2 \%$ of cases, species data within a trait were missing. In such cases, the average value for the genus was used.

\section{Data analysis}

In the following analyses we identified which underlying traits of plant species could be used to predict the success of seed collection with vacuum harvesters. The analysis was restricted to species that were recorded in at least two quadrats in the donor grasslands and covered at least $0.1 \%$ of the quadrat area. Less abundant species were omitted because their low cover could have been the reason for their absence in the analysed sample of the seed mixture. In addition shrubs (e.g. Crateagus spp.) were excluded from the analysis as they were not representative of target grassland flora, nor was their fruit likely to be collected by suction harvesting.

All analyses were undertaken using general linear mixed effects models in $\mathrm{R}$ version 3.0 (R Core Team 2015) within the lme4 package (Bates et al. 2013). We applied a multimodel inference approach using the MuMIn package (Bartoń 2013) to assess trends in individual species' collection rate index $\left(e_{s p}\right)$ to reproduction type, seed production, seed dispersal mode, time of seed shedding, seed-releasing height and habitat requirements in terms of light, soil moisture and soil fertility. The $e_{s p}$ value of each species was treated as a single data point in the analysis, with genera nested within family specified as random effects to account for the hierarchical phylogenetic structure of the data.

Rather than aiming to produce a 'potential' best-fit model, the multi-model inference approach provided an unbiased method for estimating parameter importance by considering all potential model combinations. This avoids problems associated with trying to produce a single best-fit model where the order of parameter deletion or addition can result in different combinations of fixed effects (Burnham and Anderson 1998; Symonds and Moussalli 2011). The approach used Akaike's information criterion (AIC) to compare model fit (Burnham and Anderson 1998). We assessed all possible combinations of the fixed effects, excluding interactions, and ranked these on the basis of their AIC value. Overall, we compared 1024 models including both a null model (intercept only) and a saturated global model. For each of these models an AIC difference $\left(\Delta_{\mathrm{i}}\right)$ was calculated as $\Delta_{i}=\mathrm{AIC}_{\mathrm{i}}-\mathrm{AIC}_{\min }$, where $\mathrm{AIC}_{\min }$ is the lowest recorded value for any model, and $\mathrm{AIC}_{\mathrm{i}}$ is the model-specific
AIC value. $\Delta_{\mathrm{i}}$ indicates the relative support for each model and is used to derive Akaike weights $\left(w_{\mathrm{i}}\right)$ (Burnham and Anderson 1998), which describe the probability that model $i$ would be selected as the best-fitting model if the data were collected again under identical conditions. The $w_{\mathrm{i}}$ of all $n$ models sums to 1 , so that the higher the value of this parameter the greater the weight of evidence that it has an effect on the response variable of interest.

Following Burnham and Anderson (1998), any model with a $\Delta_{\mathrm{i}}<2$ has equivalent power in explaining variation in the data relative to the identified best-fit model, i.e. that model with a $\Delta_{\mathrm{i}}$ of 0 . This is referred to as the $\Delta$ AIC $<2$ model sub-set. Within this sub-set, individual fixed effects will be represented to different extents, from inclusion within all models present in the $\Delta$ AIC $<2$ model sub-set to none. To assess the relative weight of evidence in support of each fixed effect, a variable importance score was calculated as the sum of the $\mathrm{w}_{\mathrm{i}}$ scores of models containing a given explanatory factor over the sum of $w_{i}$ scores from all models within that $\Delta \mathrm{AIC}<2$ subset. In addition, averaged parameter estimates weighted by individual model $w_{\mathrm{i}}$ scores were calculated (Burnham and Anderson 1998). Finally, as AIC provides a relative measure of model fit, we also followed the recommendations of Symonds and Moussalli (2011) and derived a marginal $R^{2}$-value for the global model, which provides an indication of goodness of fit of the models to the data.

\section{Results}

Of the 163 species recorded within the donor sites, 98 were recorded in at least two quadrats and covered at least $0.1 \%$ of the quadrats area and so were included in the following analysis. Sixty-nine species emerged from the material collected by vacuum harvesting (Online Appendix B). There was a considerable difference between the cover of species within these donor sites and their subsequent representation in the emerged material originating from the vacuum harvesting process (Table 1). Among the 69 species, only 12 were overrepresented relative to the donor sites (Online Appendix C). Of these, the species most effectively collected using vacuum harvesting were Agrostis stolonifera (Poaceae) $\left(e_{\mathrm{sp}}=2.79\right)$, Agrostis capillaris $\left(e_{\mathrm{sp}}=2.28\right)$, Plantago media (Plantaginaceae) $\left(e_{\mathrm{sp}}=1.91\right)$, Plantago lanceolata $\left(e_{\mathrm{sp}}=1.33\right)$, and Deschampsia caespitosa $\left(e_{\mathrm{sp}}=1.71\right)$ (Poaceae). Conversely, Carex davalliana (Cyperaceae), Nardus stricta (Poaceae), Phragmites australis (Poaceae), Potentilla erecta (Rosaceae) and Geum rivale (Rosaceae) obtained the lowest values of $e_{\mathrm{sp}}$ and as such were underrepresented $(-5.61,-4.05,-3.08,-4.44$, and -3.23 , respectively). The former three of these were relatively abundant in the grasslands, but were not detected in the collected seed 
Table 1 The ranked dominance of plant species in the donor site based on their average percentage cover, and that of the percentage of seedlings emerging from the vacuumharvested material

\begin{tabular}{|c|c|c|c|c|c|}
\hline \multicolumn{3}{|l|}{ Donor site percentage cover } & \multicolumn{3}{|c|}{ Percentage of emerged seedlings } \\
\hline Species & Mean (\%) & SE & Species & Mean $(\%)$ & SE \\
\hline Molinia caerulea & 19.6 & 3.8 & Galium boreale & 21.8 & 0.7 \\
\hline Galium boreale & 6.6 & 2.3 & Molinia caerulea & 18.7 & 0.7 \\
\hline Potentilla erecta & 6.0 & 1.4 & Deschampsia caespitosa & 16.8 & 0.9 \\
\hline Cirsium canum & 5.5 & 1.8 & Galium verum & 5.8 & 0.3 \\
\hline Geum rivale & 3.5 & 1.0 & Plantago lanceolata & 4.7 & 0.3 \\
\hline Centaurea jacea & 3.3 & 0.7 & Plantago media & 4.4 & 0.3 \\
\hline Deschampsia caespitosa & 2.9 & 0.7 & Pimpinella saxifraga & 4.0 & 0.3 \\
\hline Briza media & 2.9 & 0.7 & Festuca arundinacea & 2.4 & 0.2 \\
\hline Serratula tinctoria & 2.8 & 1.2 & Agrostis capillaris & 2.2 & 0.1 \\
\hline Carex davalliana & 2.6 & 1.6 & Centaurea jacea & 1.9 & 0.1 \\
\hline Sanguisorba officinalis & 2.6 & 0.5 & Serratula tinctoria & 1.7 & 0.1 \\
\hline Pimpinella saxifraga & 2.2 & 0.3 & Holcus lanatus & 1.4 & 0.1 \\
\hline Other species & 39.5 & - & Other species & 14.8 & - \\
\hline
\end{tabular}

Means and their SEs were derived from data collected in the 42 plant quadrats and the eight germination trays mixture. Three species that emerged from the vacuum-harvested material were not recorded from the donor meadows. These were Bidens tripartita (Asteraceae), Conyza canadensis (Asteraceae) and Sonchus asper (Asteraceae). The two latter species have seeds that are wind dispersed over large distances.

Of the 1024 models explaining the response of plant $e_{s p}$ scores to the plant traits, only four were represented within the $\Delta$ AIC $<2$ confidence set (Table 2 ). The global model for this relationship explained a biologically meaningful proportion of the variance in the data $\left(R_{\text {adj }}^{2}=0.41\right)$. Only three explanatory traits were present in all four models within the $\triangle \mathrm{AIC}<2$ confidence set. These were reproduction mode (e.g. the reliance on seed or vegetative reproduction), total seed production and the month of shedding ripe seeds. The overrepresentation of seedlings in the germinated material was particularly common for species that shed their seeds in late summer/early autumn. This coincided with the period over which suction harvesting occurred. Plants that influenced this result most were $D$. caespitosa, Pimpinella saxifraga (Apiaceae), and Daucus carota (Apiaceae).

In addition to these fixed effects, species traits describing light and soil moisture preferences were represented within three of the four models of the $\Delta \mathrm{AIC}<2$ confidence set. There was a positive correlation between light preference and the $e_{\mathrm{sp}}$ scores, such that shade-tolerant species tended
Table 2 The four linear mixed models $(M 1-M 4)$ within the Akaike's information criterion $(A I C)$ difference $(\triangle \mathrm{AIC})<2$ confidence set that explain the response of individual species' emergence success of the vacuum-harvested material $\left(e_{\mathrm{sp}}\right)$ to the fixed effects of individual species' traits

\begin{tabular}{|c|c|c|c|c|c|c|c|c|c|}
\hline & Seed production & $\begin{array}{l}\text { Time of seed } \\
\text { shedding }\end{array}$ & Reprod. type & Light pref. & Soil moisture pref. & $\begin{array}{l}\text { Seed disper- } \\
\text { sal by wind }\end{array}$ & AIC & $\Delta_{\mathrm{i}}$ & $W_{\mathrm{i}}$ \\
\hline M1 & 1 & 1 & 1 & 1 & 1 & & 332.5 & 0.00 & 0.39 \\
\hline M2 & 1 & 1 & 1 & 1 & & & 333.6 & 1.18 & 0.22 \\
\hline M3 & 1 & 1 & 1 & & 1 & & 333.7 & 1.29 & 0.21 \\
\hline M4 & 1 & 1 & 1 & 1 & 1 & 1 & 333.9 & 1.46 & 0.19 \\
\hline $\begin{array}{l}\text { Variable } \\
\text { importance } \\
\text { score }\end{array}$ & 1.00 & 1.00 & 1.00 & 0.79 & 0.78 & 0.19 & & & \\
\hline$\beta$ & 0.402 & 0.389 & 1.362 & 0.580 & -0.334 & 0.588 & & & \\
\hline
\end{tabular}

The inclusion of a fixed effect within each of these models is indicated by 1, while AIC scores, delta weight $(\Delta i)$ and the model selection probabilities $\left(w_{\mathrm{i}}\right)$ are provided. Parameter estimates $(\beta)$ were generated by averaging across all models within the $\Delta$ AIC $<2$ confidence set and using the selection probabilities to weight this process

Reprod. reproduction, pref. preference 
(a) Total seed production $\left(I n_{e} N+1\right)$

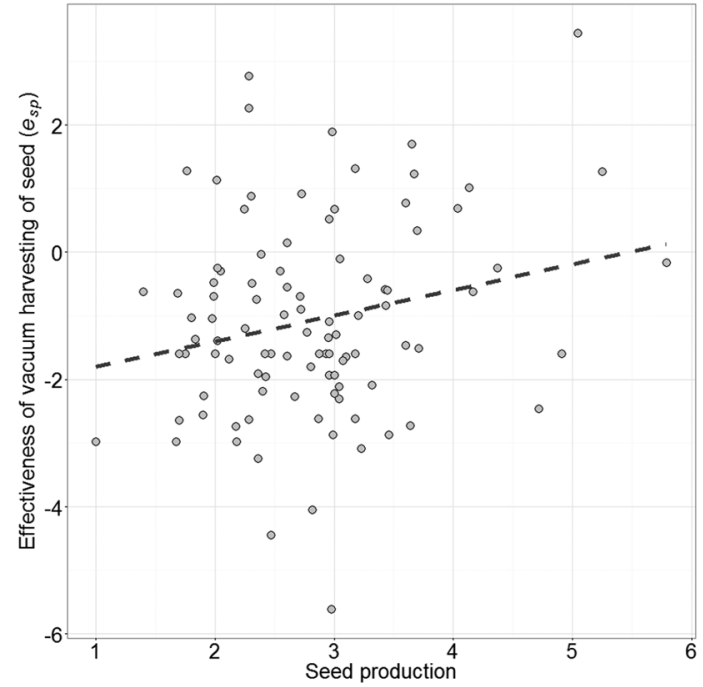

(c) Reproductive mode

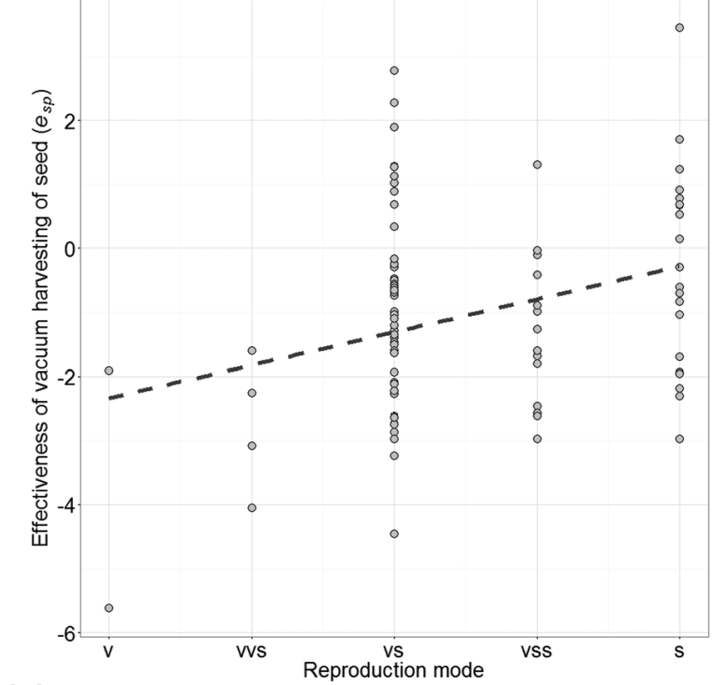

(e) Soil moisture preference index

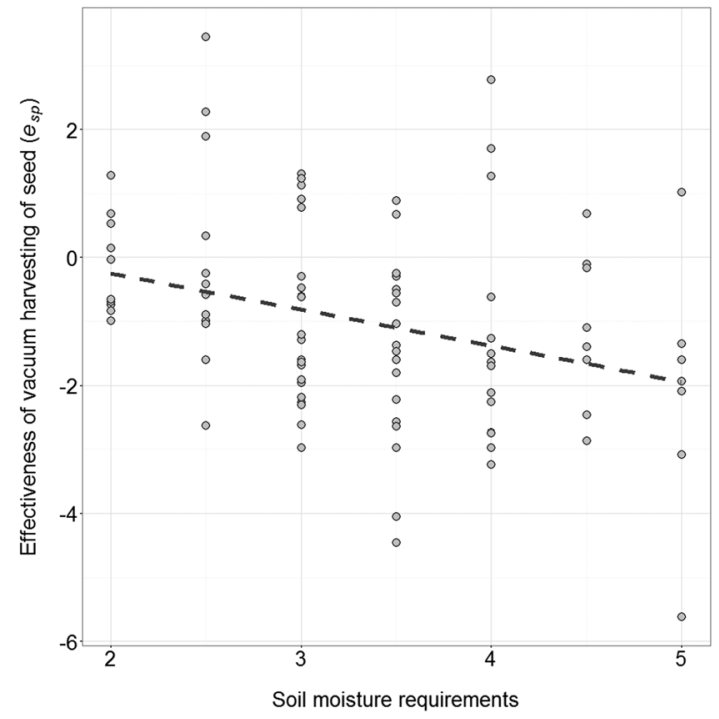

(b) Mean month of seed release

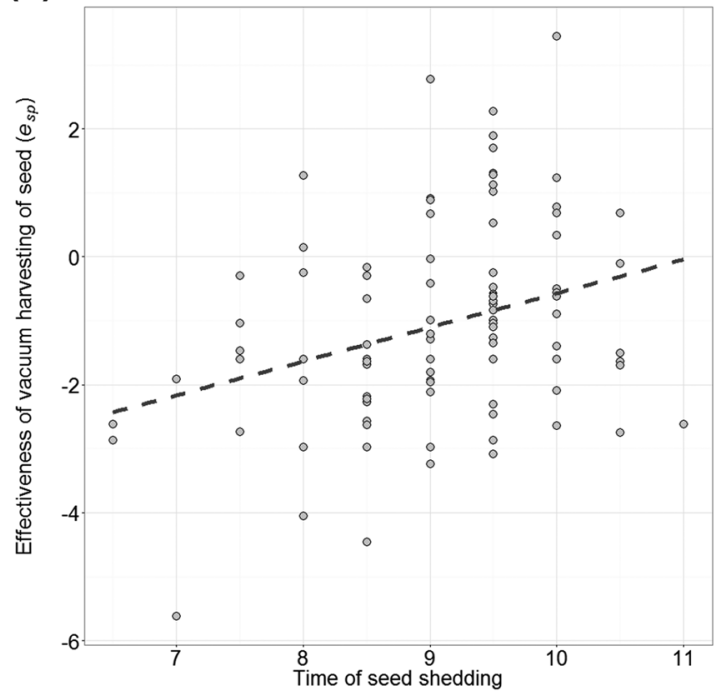

(d) Light preference index

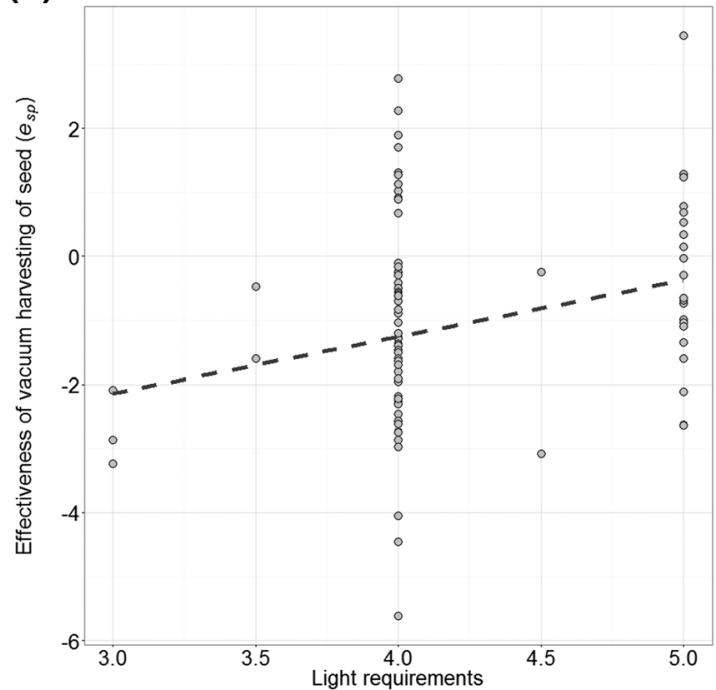

(f) Ranked wind dispersal index

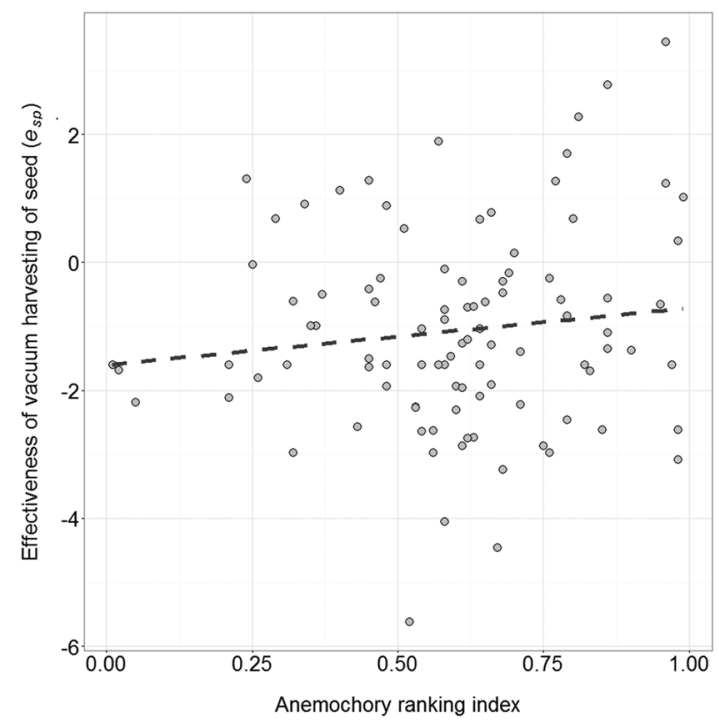


४Fig. 1 Graphs showing the emergence success of individual plant species collected using suction-harvesting techniques from speciesrich donor sites $\left(e_{\mathrm{s}}\right)$ in response to the plant functional traits of seed production, month of seed shedding, reproductive type, light preference, soil moisture preference and ranked wind dispersal index. Regression lines (dashed lines) are for univariate relationships only and are included to provide a visual reference for the relationship. $V$ Vegetative only, VVS mostly vegetative, VS vegetative and seed, VSS mostly by seed, $S$ seed

to be underrepresented in the emerging material. The model averaged parameter estimates for soil moisture preferences showed a negative correlation with the $e_{\mathrm{sp}}$ scores. Overall species adapted to dry/semi-dry soils with high light requirements had typically high $e_{\mathrm{sp}}$ scores, e.g. Galium verum (Rubiaceae), G. album, P. saxifraga, Campanula glomerata (Campanulaceae), and Helianthemum nummularium (Cistaceae), and shade-tolerant species found on moister organic soils were underrepresented in the emerging material, such as Lycopus europaeus (Lamicaeae), Filipendula ulmaria (Rosaceae), and Geum rivale (Rosaceae).

The reliance of plants on wind dispersal, as defined by the anemochory ranking index, was positively correlated with species $e_{\mathrm{sp}}$ scores. However, as this trait was only found in one of the models within the $\Delta \mathrm{AIC}<2$ confidence set there was limited evidence in support of its role in predicting seedling emergence from the harvested material (Table 2). Members of the Fabaceae, such as Vicia villosa, Vicia cracca, Lotus corniculatus and Lathyrus pratensis, were particularly likely to have high terminal velocities for their falling seeds, and as such, low anemochory ranking index values. These species typically also had low $e_{\mathrm{sp}}$ values and were underrepresented by vacuum harvesting. However, this was not limited to this family, with high terminal velocities and poor $e_{\mathrm{sp}}$ scores found for both Polygonum bistorta (Polygonaceae) and Cirsium canum (Asteraceae). Conversely, species like Conyza canadensis, Agrostis spp., S. asper, Epilobium palustre (Onagraceae), Cirsium arvense, Holcus lanatus and $D$. caespitosa all have low terminal seed velocities and are associated with high emergence rates from the suctionharvested material (Online Appendix C).

The $\Delta$ AIC $<2$ confidence set of models did not include the traits of seed-releasing height, seed longevity, or soil fertility preferences. These three traits were therefore excluded from explaining emerging trends defined by the $e_{\mathrm{sp}}$ score in the collected material.

\section{Discussion}

Nearly half of the flora found within the donor sites emerged from the harvested seed, suggesting that vacuum harvesting provided a reliable method for supplementing natural seed propagation. No impact of seed bank longevity was detected, which suggests that the portion of the emerged plants did not differ significantly among the species, regardless of their regenerative strategy (regeneration in autumn in the year of seed shedding or in the following years).

Suction sampling to collect seeds introduced bias resulting from trait characteristics of individual plant species within the donor sward (Stevenson et al. 1997; Riley et al. 2004). As may be expected, there was a slight trend whereby plants that produce large number of seeds were overrepresented, which was due to a greater probability of collection in the harvested material as a result of weight of numbers.

Of comparable importance to the number of seeds produced was the phenological overlap between the typical time of shedding of ripe seeds and the timing when the suctionharvesting operations are feasible (August-October). Plants that shed their seeds in autumn were more likely to be collected than those reaching maturity in early summer, with some suggestion that there was a decrease in emergence success for seeds collected after mid-September (Fig. 1). The consequences of this mismatch between plant phenology and the timing of seed collection is an issue not limited solely to suction-harvesting techniques (Jones et al. 1999; Grime 2002; Riley et al. 2004). Indeed, besides the collection of seeds from monocultures (e.g. agricultural crops) there would likely always be some level of mismatch in the timing of peak seed production and seed collection for at least some species. For more destructive seed-collection methods (i.e. the cutting of the sward to produce green hay) it would only be possible to have one or two harvesting times per year, potentially resulting in the loss of some plant species from the collected material. However, for non-destructive sampling methods, like suction harvesting, it would be possible to overcome this mismatch by taking multiple samples throughout the growing season.

As was predicted, vacuum harvesting favoured the collection of species that placed a greater reproductive effort into seed production, with those species that depend on vegetative reproduction being underrepresented in the emerging material. This may reflect the trade-off that results in plants producing a high quantity of smaller seeds to balance their reproductive effort (Bruun and Poschlod 2006). Although seed weight was not examined directly (due to collinearity with our index of wind dispersal), this bias may be potentially important. For example, depending on the conditions in which plants established, seed size could affect colonization success so that small seeds benefited from frequent cutting and grazing regimes, while larger seeds were more capable of establishing under increased vegetative competition (Kahmen and Poschlod 2008). The lower number of vegetatively propagating plants in the collection may also explain why the emergence of seedlings tended to increase with the individual species' light requirements and decreased with their requirements for water in soil. Plants growing in 
the denser vegetation and on less drought-prone soil types tended to rely more heavily on vegetative reproduction, a result of the selection pressure caused by a higher risk of seedling mortality due to competition (Grime 2002). This tendency may explain why those species within the donor meadows could have been underrepresented by a collection method targeted only at the removal of seeds from plants. However, this does suggest that where plants are largely obligate in their reliance on vegetative reproduction, suction sampling may be an inappropriate method for their collection. Under these circumstances alternative strategies aimed at promoting the seeds' dispersal to the restoration sites may be necessary, e.g. the use of directly planted seedlings rather than seeds (Warman et al. 2007).

There was some evidence, although less than might have been expected, that the effectiveness of vacuum harvesting increased with the wind dispersal (anemochory) potential of individual species. Indeed, the impact of this factor was smaller than the importance of traits predicting individual species' light or soil moisture requirements. The lack of importance of this dispersal mechanism may be the result of a difference between the action of vacuum harvesters and the force of wind. Specifically, the speed of air flow generated by petrol vacuum harvesters typically exceeds those that would be encountered in temperate grasslands by one order of magnitude. Seeds that would not normally be wind dispersed may still be light enough to be moved by the force generated by these suction harvesters. As such, the anemochory potential of individual plant species may be of comparatively limited importance in predicting the effectiveness of collection of their seed.

We found no relationship between the releasing height of seeds and their representation in the emerged material. This may be explained by the narrow range of seed-releasing heights considered (e.g. shrubs and trees were not part of the species pool). Nevertheless, it would appear that the structural diversity of the donor sites did not impede seed collection by suction harvesting. In this respect, vacuum harvesting may perform better than green hay collection or brush stripping of seeds, both of which have been shown to be less effective for seed set close to the ground (Kiehl et al. 2010).

Using suction sampling to collected seeds for grassland restoration may lead to fundamental differences in plant species composition between the donor sites and the receptor sites. Where priority effects linked to the order of species establishment have long-term consequences, such differences may be either hard to overcome using subsequent management, or even permanent (Young et al. 2005). For example, the high emergence rates of competitive grass species from the collected material (e.g. D. caespitosa, H. lanatus and A. stolonifera) may suppress the establishment of other important plants in the long term (Fagan et al. 2008). Despite the bias associated with the composition of species collected by vacuum harvesting, hand-held suction devices are a highly flexible tool that have the potential to be used to increase the representation of certain species within the collected material. This can be achieved by using a focused sampling regime that targets underrepresented species for seed collection, or alternatively actively avoids areas with unwanted species such as pernicious weeds (Stevenson et al. 1997; Riley et al. 2004). The precision of hand-held suction devices, assuming the user has sufficient taxonomic expertise, may therefore make vacuum techniques a more effective tool for wild seed collection than industrial-scale methods using large cutting booms (e.g. $>2 \mathrm{~m}$ in length) (Morgan and Collicutt 1994; Jones et al. 1999; Pywell et al. 2003; Edwards et al. 2007). However, a priori knowledge of which species are underrepresented by the collection method remains vital to the success of this approach.

\section{Conclusion}

Vacuum harvesting from donor sites provides a practical method for sourcing seeds of local provenance. However, species' shares in the collected seed mixture were not proportional to their cover within the donor sites. Individual species' traits affected the success with which seeds were collected and subsequently emerged. The highest levels of emergence were exhibited by species: (1) with seed-based dispersal, (2) that produce large numbers of seed, (3) that shed seeds in the summer/fall, (4) are drought tolerant, and (5) require much light. This study sets a reference that can help in the design of collection campaigns for targeted underrepresented species of high importance for conservation. Due to the trait-based analytical approach used, the application of the results is not restricted to the vegetation of the Bagno Serebryskie Nature Reserve. Ultimately, the practical viability of vacuum harvesting is linked to its low equipment costs, although this is countered by the large investment in operational hours needed to collect material. As such, these methods may be more suited for use in nature reserves where volunteer labour can make this trade-off between the cost of machinery and time more favourable.

Acknowledgements The experiment was co-founded within the framework of the Butterfly Meadows LIFE project (LIFE06 NAT/ PL/000100) and as a statutory task of the Institute of Technology and Life Sciences, Poland. This research could not have been undertaken without support from Wiktor Kotowski, who bought one of the vacuum harvesters and provided taxonomic advice. During the research mainly free/open-source software was used: Linux OS, R-project package and several R libraries, LibreOffice, Zotero, and QuantumGIS. The first author thanks all those who contributed to the creation of these nonproprietary programs. We declare that the experiments performed comply with the current laws of Poland.

Open Access This article is distributed under the terms of the Creative Commons Attribution 4.0 International License (http://creativecomm 
ons.org/licenses/by/4.0/), which permits unrestricted use, distribution, and reproduction in any medium, provided you give appropriate credit to the original author(s) and the source, provide a link to the Creative Commons license, and indicate if changes were made.

\section{References}

Bartoń K (2013) MuMIn: multi-model inference. R package version 1.9.13

Bates D, Maechler M, Bolker B (2013) lme4: linear mixed-effects models using S4 classes. R package version 0.999999-2

Bischoff A (2002) Dispersal and establishment of floodplain grassland species as limiting factors in restoration. Biol Conserv 104:25-33

Briggs A (2001) Harvesting native grasses-innovation and development in the Central West. In: Second National Conference Proceedings. University of Melbourne, Institute of Land and Food Resources, Dookie, VIC, Australia. http://www.regional.org.au/ au/stipa/2001/p-06.htm\#TopOfPage. Accessed 7 Oct 2016

Bruun HH, Poschlod P (2006) Why are small seeds dispersed through animal guts: large numbers or seed size per se? Oikos 113:402-411

Burnham KP, Anderson DR (1998) Model selection and multimodel inference: a practice information-theoretic approach. Springer, New York

Coates W (2015) Blown away. Grounds maintenance. http://grou nds-mag.com/equipment/grounds_maintenance_blown_away. Accessed 8 Oct 2016

Core Team R (2015) R: a language and environment for statistical computing. R Foundation for Statistical Computing, Vienna

Donath TW, Holzel N, Otte A (2003) The impact of site conditions and seed dispersal on restoration success in alluvial meadows. Appl Veg Sci 6:13-22

Edwards A, Mortimer SR, Lawson CS, Westbury DB, Harris SJ, Woodcock BA, Brown VK (2007) Hay strewing, brush harvesting of seed and soil disturbance as tools for the enhancement of botanical diversity in grasslands. Biol Conserv 134:372-382

Fagan KC, Pywell RF, Bullock JM, Marrs RH (2008) Do restored calcareous grasslands on former arable fields resemble ancient targets? The effect of time, methods and environment on outcomes. J Appl Ecol 45:1293-1303

Ghazoul J (2005) Pollen and seed dispersal among dispersed plants. Biol Rev 80:413-443

Greene DF, Johnson EA (1993) Seed mass and dispersal capacity in wind-dispersed diaspores. Oikos 67:69-74

Grime JP (2002) Plant strategies, vegetation processes, and ecosystem properties, 2nd edn. Wiley, Chichester

Hintze C, Heydel F, Hoppe C, Cunze S, König A, Tackenberg O (2013) $\mathrm{D}^{3}$ : the dispersal and diaspore database - baseline data and statistics on seed dispersal. Perspect Plant Ecol Evol Syst 15: 180-192. http://www.seed-dispersal.info. Accessed 12 Oct 2016

Jones GH, Trueman IC, Millet P (1999) The use of hay strewing to create species-rich grasslands. I. General principles and hay strewing versus seed mixes. Land Contam Reclam 3:104-107

Kącki Z, Czarniecka M, Swacha G (2013) Statistical determination of diagnostic, constant and dominant species of the higher vegetation units of Poland. Societas Botanicorum Poloniae, Łódź

Kahmen S, Poschlod P (2008) Does germination success differ with respect to seed mass and germination season? Experimental testing of plant functional trait responses to grassland management. Ann Bot Lond 101:541-548

Kalmbacher R, Cellinese N, Frank M (2005) Seeds obtained by vacuuming the soil surface after fire compared with soil seedbank in a flatwoods plant community. Native Plants 6:233-241
Kiehl K, Kirmer A, Donath TW, Rasran L, Hoelzel N (2010) Species introduction in restoration projects-evaluation of different techniques for the establishment of semi-natural grasslands in Central and Northwestern Europe. Basic Appl Ecol 11:285-299

Kioritz (2008) Echo service information. Document reference no. 21-25F-00. http://www.echojapan.cz/wp-content/uploads/PB255ES+ES-255ES_21-25F-00.pdf. Accessed 12 Oct 2016

Kleyer M, Bekker RM, Knevel IC, Bakker JP, Thompson K, Sonnenschein M, Poschlod P, Van Groenendael JM, Klimeš L, Klimešová J, Klotz S, Rusch GM, Hermy M, Adriaens D, Boedeltje G, Bossuyt B, Dannemann A, Endels P, Götzenberger L, Hodgson JG, Jackel A-K, Kühn I, Kunzmann D, Ozinga WA, Römermann C, Stadler M, Schlegelmilch J, Steendam HJ, Tackenberg O, Wilmann B, Cornelissen JHC, Eriksson O, Garnier E, Peco B (2008) The LEDA Traibase: a database of life-history traits of the Northwest European flora. J Ecol 96:1266-1274

Klotz S, Kühn I, Durka W (eds) (2002) BIOLFLOR-Eine Datenbank zu biologisch-ökologischen Merkmalen der Gefäßpflanzen in Deutschland. Bundesamt für Naturschutz, Bonn

Morgan JP, Collicutt DR (1994) Seed stripper harvesters. Restor Manage Notes 12:51-54

Natura 2000 webpage of Poland (online). http://natura2000.gdos.gov. $\mathrm{pl} /$ datafiles. Accessed 26 Oct 2016

Oberdorfer E (1994) Pflanzensoziologische Exkursionsflora, 7th edn. Ulmer, Stuttgart

Pywell RF, Bullock JM, Roy DB, Warman EA, Walker KJ, Rothery $\mathrm{P}$ (2003) Plant traits as predictors of performance in ecological restoration. J Appl Ecol 40:65-77

Riley JD, Craft IW, Rimmer DL, Smith RS (2004) Restoration of magnesian limestone grassland: optimizing the time for seed collection by vacuum harvesting. Restor Ecol 12:311-317

Scotton M, Rieger E, Feucht B, Tamegger C, Jahn F, Ševčíková M, Semanová I, Krautzer B, Graiss W, Haslgruebler P, Kirmer A, Stolle M (2011) Methods of seed harvesting in species-rich grasslands. In: Scotton M, Kirmer A, Krautzer B (eds) Practical handbook for seed harvest and ecological restoration of species-rich grasslands. Cooperativa Libraria Editrice Università di Padova, Padova, pp 26-39

Stevenson MJ, Ward LK, Pywell RF (1997) Re-creating semi-natural communities: vacuum harvesting and hand collection of seed on calcareous grassland. Restor Ecol 5:66-76

Symonds ME, Moussalli A (2011) A brief guide to model selection, multimodel inference and model averaging in behavioral ecology using Akaike's information criterion. Behav Ecol Sociobiol 65:13-21

Thomson FJ, Moles AT, Auld TD, Kingsford RT (2011) Seed dispersal distance is more strongly correlated with plant height than with seed mass. J Ecol 99:1299-1307

Warman EA, Pywell RF, Walker KJ, Bullock JM (2007) Survival of plug plants under different grassland management regimes. Asp Appl Biol 82:109-116

Woodcock BA, Mcdonald AW, Pywell RF (2011) Can long-term floodplain meadow recreation replicate species composition and functional characteristics of target grasslands? J Appl Ecol 48:1070-1078

Young TP, Petersen DA, Clary JJ (2005) The ecology of restoration: historical links, emerging issues and unexplored realms. Ecol Lett 8:662-673

Zarzycki K, Trzcińska-Tacik H, Różański W, Szeląg Z, Wołek J, Korzeniak U (2002) Ecological indicator values of vascular plants of Poland. Jagiellonian University, Cracow 